CLINICAL STUDY

\title{
Overall and cause-specific mortality in GH-deficient adults on GH replacement
}

\author{
Rolf C Gaillard*, Anders F Mattsson ${ }^{1}$, Ann-Charlotte Åkerblad ${ }^{1}$, Bengt-Åke Bengtsson ${ }^{2}$, José Cara ${ }^{3}$, \\ Ulla Feldt-Rasmussen $^{4}$, Maria Koltowska-Häggström ${ }^{1}$, John P Monson ${ }^{5}$, Bernhard Saller ${ }^{6}$, Patrick Wilton ${ }^{3}$ \\ and Roger $\mathrm{Abs}^{7}$ \\ Department of Endocrinology, Diabetology and Metabolism, Centre Hospitalier Universitaire Vaudois, Lausanne, Switzerland, ${ }^{1}$ KIMS Medical Outcomes, \\ Pfizer Endocrine Care, Sollentuna, Sweden, ${ }^{2}$ Department of Endocrinology, Sahlgrenska Academy, Gothenburg University, Gothenburg, Sweden, \\ ${ }^{3}$ Pfizer Endocrine Care, New York, New York, USA, ${ }^{4}$ National University Hospital, Copenhagen, Denmark, ${ }^{5}$ Centre for Clinical Endocrinology, \\ St Bartholomew's Hospital, William Harvey Research Institute, Queen Mary, University of London, London, UK, ${ }^{6}$ Pfizer Endocrine Care Europe, \\ Tadworth, UK and ${ }^{7}$ Antwerp Centre for Endocrinology, Antwerp, Belgium \\ (Correspondence should be addressed to R Abs who is now at Antwerp Centre for Endocrinology, Grote Steenweg 556, B-2600 Berchem Antwerpen, \\ Belgium; Email: rogerabs@skynet.be) \\ *(R C Gaillard sadly passed away after completion of the manuscript and prior to submission)
}

\begin{abstract}
Objective: Hypopituitarism is associated with an increased mortality rate but the reasons underlying this have not been fully elucidated. The purpose of this study was to evaluate mortality and associated factors within a large GH-replaced population of hypopituitary patients.

Design: In KIMS (Pfizer International Metabolic Database) 13983 GH-deficient patients with 69056 patient-years of follow-up were available.

Methods: This study analysed standardised mortality ratios (SMRs) by Poisson regression. IGF1 SDS was used as an indicator of adequacy of GH replacement. Statistical significance was set to $P<0.05$. Results: All-cause mortality was 13\% higher compared with normal population rates (SMR, 1.13; 95\% confidence interval, 1.04-1.24). Significant associations were female gender, younger age at followup, underlying diagnosis of Cushing's disease, craniopharyngioma and aggressive tumour and presence of diabetes insipidus. After controlling for confounding factors, there were statistically significant negative associations between IGF1 SDS after 1, 2 and 3 years of GH replacement and SMR. For cause-specific mortality there was a negative association between 1-year IGF1 SDS and SMR for deaths from cardiovascular diseases $(P=0.017)$ and malignancies $(P=0.044)$.

Conclusions: GH-replaced patients with hypopituitarism demonstrated a modest increase in mortality rate; this appears lower than that previously published in GH-deficient patients. Factors associated with increased mortality included female gender, younger attained age, aetiology and lower IGF1 SDS during therapy. These data indicate that GH replacement in hypopituitary adults with GH deficiency may be considered a safe treatment.
\end{abstract}

European Journal of Endocrinology 166 1069-1077

\section{Introduction}

It is well-established that mortality is increased in patients with hypopituitarism $(1,2,3,4,5,6,7,8,9)$. Recently, an extensive review was devoted to this subject (10). Cardiovascular disease is thought to be mainly responsible for this increase in mortality and female gender, age at diagnosis, craniopharyngioma and gonadotropin deficiency have been identified as risk factors $(1,2,3,4)$. It has been hypothesised that un treated GH deficiency (GHD) may also play a role (1).

During the past two decades, evidence has emerged linking hypopituitarism with cardiovascular risk factors, including hyperlipidaemia $(11,12,13,14)$, visceral adiposity $(15,16)$, insulin resistance $(17)$ and vascular endothelial dysfunction $(18,19,20)$.
Although these variables are favourably influenced by GH replacement therapy $(14,15,21,22,23,24)$, an overall impact of GH treatment on mortality could only be demonstrated by a randomised controlled trial. Since concerns have been raised regarding the long-term safety of GH therapy (25), the present descriptive study evaluated data from patients with hypopituitarism enrolled in KIMS (Pfizer International Metabolic Database) in order to identify factors associated with mortality in adults with hypopituitarism.

\section{Materials and methods}

KIMS is a global, multicentre, non-interventional, pharmacoepidemiological study in which data are 
collected from adults with GHD who are receiving recombinant human $\mathrm{GH}$ replacement therapy (somatropin, Genotropin; Pfizer, Inc., Strängnäs, Sweden) and are monitored according to routine clinical practice (26). The study protocol requires that physicians report all adverse events in patients enrolled in KIMS, including deaths, regardless of whether they are suspected to be related to GH treatment. This analysis was performed on all patient data available in the KIMS database as of March 16, 2011. Informed consent was obtained from patients in accordance with local regulations.

\section{Patient characteristics}

The present study evaluated data from all hypopituitary patients enrolled in KIMS with the exception of those with idiopathic isolated GHD of adult-onset $(n=13$ 983; 69056 patient-years). Males numbered 7174 (51.3\%; 35403 patient-years) and females 6809 (48.7\%; 33653 patient-years). Patient-years were calculated from date of KIMS entry, or the start date of GH replacement if later than KIMS entry, to the date of last recorded visit or the date of death. GHD was diagnosed according to established criteria (27).

Patients included in the study cohort had a mean age ( \pm s.D. $)$ of $34.0 \pm 18.3$ years at diagnosis of pituitary disease, $43.8 \pm 15.4$ years at enrolment in KIMS and $48.7 \pm 15.9$ years at end of follow-up, with no gender differences. The mean duration of follow-up in KIMS was 4.9 years (maximum, 16.7 years). Adult-onset pituitary disease accounted for $77 \%$ of patients and childhood-onset disease accounted for the remainder. Mean ages at diagnosis of pituitary disease, at enrolment in KIMS and at end of follow-up were: $10.8 \pm 8.2,26.9 \pm 9.9$ and $31.7 \pm 10.8$ years respectively for childhood-onset patients; and $40.9 \pm 14.3$, $48.8 \pm 13.0$ and $53.8 \pm 13.4$ years respectively for adult-onset patients. The total study cohort included patients naïve to $\mathrm{GH}$ replacement therapy $(57 \%)$, patients previously treated with $\mathrm{GH}$ who were without GH replacement for at least 6 months prior to enrolment in KIMS (15\%), and patients on GH replacement (28\%) therapy at the time of study enrolment.

Patients were divided into eight categories based on the reported aetiology of hypopituitarism, as specified in Table 1. Patients with hypopituitarism due to mass lesions $(n=8474)$ were additionally divided into seven groups according to the treatment modality (surgery, radiotherapy or a combination of modalities) of their primary disease. Causes of death were classified according to the World Health Organization (WHO) Global Burden of Disease (GBD) cause categories (28). Cross-check of the Swedish patients with the Swedish National Causes of Death Register showed a high completeness of death reporting in the KIMS database (Trial Form Support AB, Lund, Sweden, 2009, internal report).
Table 1 Aetiology of hypopituitarism, with number of patients and patient-years by category.

\begin{tabular}{|c|c|c|c|}
\hline $\begin{array}{l}\text { Aetiology } \\
\text { category }\end{array}$ & $\begin{array}{l}\text { Category } \\
\text { components }\end{array}$ & $n$ & $\begin{array}{l}\text { Patient- } \\
\text { years }\end{array}$ \\
\hline Pituitary adenoma & $\begin{array}{l}\text { Non-functioning } \\
\text { adenoma } \\
\text { Prolactinoma } \\
\text { Gonadotropinoma } \\
\text { Thyrotropinoma }\end{array}$ & 5261 & 28065 \\
\hline Cushing's disease & Cushing's disease & 859 & 4814 \\
\hline Acromegaly & Acromegaly & 239 & 1396 \\
\hline Pituitary atrophy & $\begin{array}{l}\text { Congenital } \\
\text { Idiopathic } \\
\text { Empty sella }\end{array}$ & 2496 & 10535 \\
\hline Craniopharyngioma & Craniopharyngioma & 1562 & 8392 \\
\hline Benign tumour/lesion & $\begin{array}{l}\text { Hamartoma } \\
\text { Cyst } \\
\text { Meningioma } \\
\text { Schwannoma }\end{array}$ & 462 & 2114 \\
\hline $\begin{array}{l}\text { Aggressive tumour } \\
\text { (+haematological } \\
\text { neoplasm) }\end{array}$ & $\begin{array}{l}\text { Germ cell tumour } \\
\text { Glioma } \\
\text { Chordoma } \\
\text { Sarcoma } \\
\text { Astrocytoma } \\
\text { Ependymoma } \\
\text { Medulloblastoma } \\
\text { Leukaemia } \\
\text { Lymphoma }\end{array}$ & 1135 & 5552 \\
\hline $\begin{array}{l}\text { Miscellaneous } \\
\text { aetiology }\end{array}$ & $\begin{array}{l}\text { Traumatic brain } \\
\text { injury } \\
\text { Subarachnoid } \\
\text { haemorrhage } \\
\text { Aneurysm } \\
\text { Sheehan's syndrome } \\
\text { Hydrocephalus } \\
\text { Granulomatosis } \\
\text { Histiocytosis } \\
\text { Hypophysitis } \\
\text { Haemochromatosis } \\
\text { Missing aetiology }\end{array}$ & 1969 & 8189 \\
\hline
\end{tabular}

\section{Measurement of IGF1}

Between 1994 and October 1997, measurements of serum IGF1 were performed at Kabi Pharmacia, Stockholm, Sweden, and thereafter at Sahlgrenska University Hospital, Gothenburg, Sweden, using the following assay methods: until November 2002, RIA after acid/ethanol precipitation of IGF-binding proteins (Nichols Institute Diagnostic, San Clemente, CA, USA); until September 2006, chemiluminiscence immunoassay (Nichols Advantage System); and after September 2006, Immulite 2500 (DPC Siemens, Deerfield, IL, USA) (29). For each assay, age- and gender-specific reference ranges expressed in micrograms per litre were used to calculate IGF1 SDS. Between assay reference ranges and consistency of IGF1 SDS values were validated internally. The algorithm formulae used were as follows: between 1994 and 1997, SDS $=(\ln (\mathrm{IGF} 1)-$ (5.95-0.0197 $\times$ age))/0.282; between 1997 and 2002, SDS $=(\ln ($ IGF 1$)-(5.92-0.0146 \times$ age $)) / 0.272$; and after 2002, as reported by Brabant et al. (30). 


\section{Statistical analysis}

Mortality in the study population was compared with that in a general reference population using the standardised mortality ratio (SMR), defined as the ratio between the observed and expected number of deaths encountered during the period of observation, as measured in patient-years. The observed number of deaths included all reported deaths that occurred during KIMS follow-up, and patient-years were calculated from the date of KIMS entry, or the start date of GH replacement if later than date of KIMS entry, until the last recorded visit or date of death (if date of death was known). The expected number of deaths was computed based on the 2004 update on general population estimates of mortality (GBD project published by the WHO 2008) (28) and the number of patient-years in the KIMS study cohort, as defined above. Stratification was performed by gender, attained age during the course of follow-up and the patient's respective WHO country or region, following the classification used in the WHO GBD project (28). Additional control for attained age by means of regression methods was necessary in the SMR comparisons due to large age differences between patient groups and large variation in background mortality rates. Causes of death were established for all but 80 of the 528 deceased patients: deaths with unknown cause were distributed proportionally using an average case adjustment factor of 528/(528-80) for cause-specific analyses.

Exposures to lipid-lowering and anti-hypertensive drugs were analysed as time-dependent variables (covariates); patients were switched from a non-treated to a treated category for each type of concomitant medication based on the reported start date.

The relationship between IGF1 SDS and SMR was analysed on data from 5932, 5508 and 4624 patients for whom centrally measured IGF1 values were available 1, 2 and 3 years after KIMS enrolment respectively. In these analyses, the first-, the first 2and the first 3-year data respectively were censored.

SMR was also calculated in a sub-group of 8474 patients with an intracranial tumour according to whether or not they received radiotherapy of the primary tumour, i.e. before start of GH treatment.

The observed number of deaths was assumed to follow a Poisson distribution. Byar's approximation formula was used to calculate the $95 \%$ confidence interval (95\% CI) (31).

More detailed modelling of SMR, incorporating modification terms, was performed using Poisson regression (PROC GENMOD, SAS Software Version 9; SAS, Marlow, UK) fitted on grouped data. Analyses were performed with external reference and for the IGF1 SDS analyses also with internal reference. The analyses used the expected values as an offset variable in the external reference analyses and patient-years in the internal reference analyses. Mean values for each category were used for numerical variables. $P$ values from significance tests were likelihood based. Significance level was set at $P<0.05$.

The analyses based on the full KIMS study cohort of 13983 patients included all variables showing significant heterogeneity and potentially confounding variables (gender, age at onset, attained age, duration of follow-up after KIMS entry, aetiology of primary disease, number of additional pituitary deficiencies, presence of diabetes insipidus at KIMS entry, GH treatment status at KIMS entry and use of anti-hypertensive drugs and lipid-lowering drugs).

In the multiple regression setting, the model adjusted SMR estimates for IGF1 SDS and primary radiotherapy were adjusted according to the structure of the final regression model fitted on the full data set.

\section{Results}

\section{Basic analysis of mortality}

Overall, there were 528 observed deaths vs 465.5 expected deaths during the 69056 patient-years of follow-up, indicating that mortality in the KIMS study cohort (SMR, 1.13; 95\% CI, 1.04-1.24) was slightly but significantly increased compared with the reference rate.

Gender There were 303 observed vs 321.3 expected male deaths and 225 observed vs 144.2 expected female deaths. Compared with the reference population, mortality in female patients was significantly higher (SMR, 1.56; 95\% CI, 1.36-1.78), but within the expected range in male patients (SMR, 0.94; 95\% CI, 0.84-1.06).

Age Attained age at follow-up was inversely associated with mortality $(P$ trend $<0.0001$; Fig. 1a). SMR in the
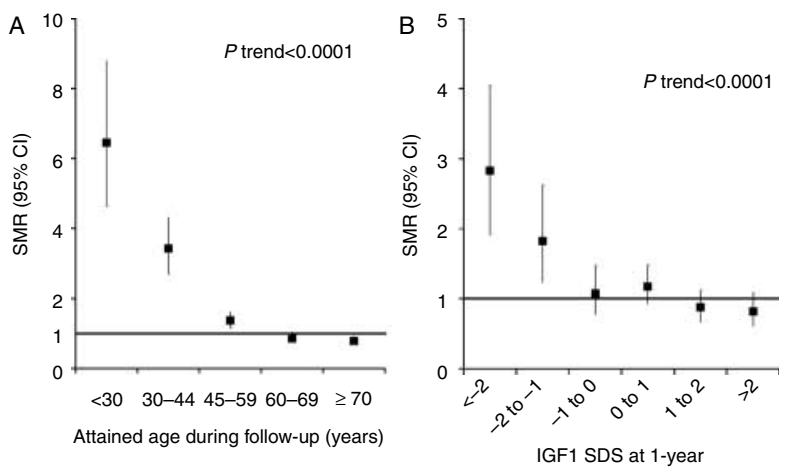

Figure 1 Relationship between SMR (shown as closed squares) and (a) attained age during follow-up and (b) IGF1 SDS at the 1 -year visit for GH-replaced hypopituitary patients in the KIMS study population. The SMR and corresponding $95 \% \mathrm{Cl}$ were calculated for each age category and IGF1 SDS category. The trend of decreasing SMR was statistically significant with increasing age category $(P$ trend $<0.0001)$ and with increasing IGF1 SDS $(P$ trend $<0.0001)$. The solid line at $S M R=1$ represents the point at which mortality is equivalent to that expected in the general population. Vertical bars correspond to $95 \% \mathrm{Cl}$. 
group of childhood-onset patients was $2.92(95 \%$ CI, 2.25-3.72) and in the group of adult-onset patients 1.04 (95\% CI, 0.95-1.14), but after controlling for attained age during follow-up no significant differences were observed between these onset groups $(P=0.22)$. The onset-specific estimated change in SMR per year of attained age was $-3.95 \%(95 \% \mathrm{CI},-6.14$ to $-1.71 \%$; $P=0.0006)$ for the childhood-onset group and $-2.65 \%$ $(95 \% \mathrm{CI},-3.43$ to $-1.86 \% ; P<0.0001)$ for the adultonset group. The interaction effect between disease onset and attained age was not significant $(P=0.31)$.

Country Of the total KIMS study cohort, 10497 patients $(75 \%)$ came from six countries comprising 58967 patients-years (85\%) of follow-up. This group accounted for 455 deaths, resulting in an overall SMR of 1.14 (95\% CI, 1.04-1.25). The SMR was increased for Belgium (1.47; 95\% CI, 1.12-1.90), UK (1.43; 95\% CI, $1.22-1.68)$ and Sweden (1.23; 95\% CI, 1.02-1.46); near unity for the Netherlands $(0.89$; $95 \%$ CI, $0.64-$ $1.21)$ and Spain (0.70; 95\% CI, 0.36-1.22); and decreased for Germany $(0.72$; 95\% CI, 0.55-0.92). The overall SMR for the remaining 25 countries was 1.11 (95\% CI, 0.87-1.40).

Aetiology of hypopituitarism Significantly elevated SMR was seen in patients with Cushing's disease, craniopharyngiomas and aggressive tumours (Fig. 2). For all aetiological categories, SMR remained inversely associated with attained age and was increased in females.

Treatment of primary disease Differences in SMR were noted between treatment groups (Fig. 2). Increased SMR was observed in patients who underwent transcranial surgery and/or radiotherapy of the primary tumour.
Pituitary hormone deficiencies Relative to the overall SMR for the study cohort, the number of additional pituitary hormone deficiencies reported at KIMS entry was not associated with an increase or decrease in all-cause mortality (data not shown). However, the presence of diabetes insipidus at KIMS entry was associated with a significant increase in all-cause mortality with an SMR of 1.76 (95\% CI, 1.49-2.07), regardless of the number of additional pituitary hormone deficits.

IGF1 Mean IGF1 SDS at year 1 of follow-up in the total study cohort was $0.54 \pm 1.77$ in males and $-0.16 \pm 1.67$ in females. Mean GH dose at year 1 was $0.39 \pm 0.25 \mathrm{mg} /$ day (median, $0.33 \mathrm{mg} /$ day) for males and $0.46 \pm 0.29 \mathrm{mg} /$ day (median, $0.40 \mathrm{mg} /$ day) for females. IGF1 SDS values at year 1 (Fig. 1b), year 2 and 3 (results not shown) were negatively associated with mortality with no observed gender differences. Moreover, IGF1 SDS at year 1 had a similar influence on SMR for each aetiological category (data not shown).

In patients naïve to $\mathrm{GH}$ replacement therapy $(n=3389$; patient-years, 19 583), mean IGF1 SDS at baseline was $-1.72 \pm 1.75$ (males: $-1.47 \pm 1.67$; females: $-1.96 \pm 1.80)$. In these patients, each IGF1 SDS unit increase (e.g. -1 to $0,0-1,1-2$ ) was associated with a $16 \%(95 \%$ CI, 6-24; $P=0.002)$ decrease in SMR. Moreover, after adjustment for baseline IGF1 SDS, each unit gain in IGF1 SDS during the first year of $\mathrm{GH}$ replacement was associated with an average decrease in SMR of $11 \%(95 \%$ CI, 1-21; $P=0.04)$. A significant negative relationship was also observed between relative $\mathrm{GH}$ sensitivity (defined as $\triangle$ IGF 1 SDS/GH dose) and SMR with a $7 \%$ decrease in SMR for each unit increase in GH sensitivity (95\% CI, 1-13; $P=0.03$; controlling for baseline IGF1 SDS).

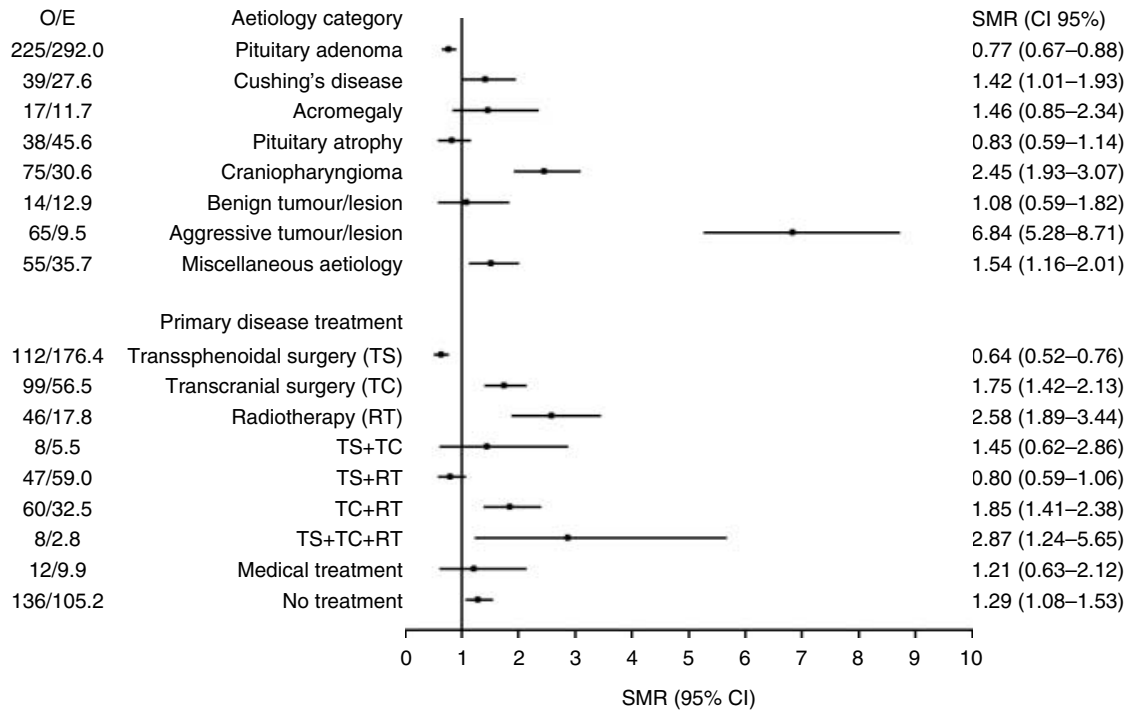

Figure 2 Overall mortality for GH-replaced hypopituitary patients in the KIMS study population in relation to aetiology and treatment of the primary disease. The SMR (shown as closed circles) and associated $95 \% \mathrm{Cl}$ were plotted for each category of disease aetiology and primary disease treatment category respectively. The observed (O) and expected $(\mathrm{E})$ numbers of deaths for each category are also shown. 
Table 2 SMRs from the multiple regression model. SMR estimates for the aetiology categories assume an equal gender distribution and are presented at attained age of 50 years with no diabetes insipidus and not taking anti-hypertensive drugs.

\begin{tabular}{|c|c|c|c|c|}
\hline SMR & $\begin{array}{l}\text { SMR } \\
\text { estimate }\end{array}$ & $95 \% \mathrm{Cl}$ & $\chi^{2}$ & $\operatorname{Pr}>\chi^{2}$ \\
\hline Female vs male ratio & 1.59 & 1.33 to 1.90 & 26.24 & $<0.0001$ \\
\hline $\begin{array}{l}\text { Percentage change/year of attained age for pituitary adenoma, } \\
\text { Cushing's disease, acromegaly }\end{array}$ & -1.3 & -2.4 to -0.2 & 5.32 & 0.021 \\
\hline $\begin{array}{l}\text { Percentage change/year of attained age for all aetiologies, except } \\
\text { pituitary adenoma, Cushing's disease, acromegaly }\end{array}$ & -3.9 & -4.7 to -3.1 & 87.52 & $<0.0001$ \\
\hline Pituitary adenomas vs normal population & 0.89 & 0.72 to 1.12 & 0.98 & 0.32 \\
\hline Cushing's disease vs normal population & 1.25 & 0.88 to 1.79 & 1.54 & 0.22 \\
\hline Acromegaly vs normal population & 1.54 & 0.93 to 2.55 & 2.86 & 0.091 \\
\hline Pituitary atrophy vs normal population & 1.00 & 0.72 to 1.38 & 0.00 & 0.98 \\
\hline Craniopharyngioma vs normal population & 2.32 & 1.77 to 3.04 & 36.88 & $<0.0001$ \\
\hline Benign tumour/lesion vs normal population & 1.36 & 0.80 to 2.33 & 1.29 & 0.26 \\
\hline Aggressive tumour/lesion vs normal population & 4.94 & 3.76 to 6.49 & 131.54 & $<0.0001$ \\
\hline Miscellaneous aetiology vs normal population & 1.72 & 1.30 to 2.27 & 14.60 & 0.0001 \\
\hline Diabetes insipidus vs no diabetes insipidus ratio & 1.34 & 1.09 to 1.65 & 7.75 & 0.0054 \\
\hline Anti-hypertensive drugs vs no anti-hypertensive drugs ratio & 1.38 & 1.13 to 1.68 & 9.87 & 0.0017 \\
\hline
\end{tabular}

\section{Multiple poisson regression analysis}

SMR was observed to be significantly higher in females, younger patients, specific aetiologies, diabetes insipidus and hypertension (Table 2). The association between SMR and gender, attained age and diabetes insipidus held across all aetiological categories. The increased mortality observed in patients who received radiotherapy was similar to that observed in the univariate analysis. There was no significant association between SMR and lipid-lowering therapy.

The relationship between IGF1 SDS at years 1,2 and 3 and SMR remained significant in the multiple regression analysis both in the model with external reference (data not shown) and in the model with internal reference (Table 3). Each increase in IGF1 SDS unit at year 1 was associated with a decrease in SMR of 10.8\% (95\% CI, 3.9-17.2; $P=0.003$; with adjustment for variables as in the final regression model, i.e. gender, attained age, aetiology, diabetes insipidus, use of antihypertensive drugs and, additionally, anti-lipid drugs). A simplified model with adjustment for attained age and gender showed very similar results compared with the final regression model (data not shown). Similar and statistically significant adjusted estimates were observed for SMR and IGF1 SDS at 2- and 3-year visits (data not shown).

\section{Causes of death}

Although cardiovascular disease and malignancy were the leading causes of death, the overall SMR for these cause categories was not significantly increased (Fig. 3). Two other frequent causes of death, cerebrovascular disease (irrespective of primary radiotherapy) and infectious diseases, were associated with a significantly increased SMR. Of the 86 patients whose deaths were due to infectious diseases, $71(82.6 \%)$ had ACTH deficiency and were receiving glucocorticoid replacement therapy. Further, the risk of death from infectious diseases was 1.6-fold higher in patients with ACTH deficiency than in patients without ACTH deficiency (95\% CI, 0.9-2.8; $P=0.088$ ). Progression of primary tumour and endocrine complications (adrenal crisis in ACTH deficiency, ionic disturbances in ADH deficiency) were also associated with an increased SMR.

Analysis of the relationship between IGF1 SDS and cause-specific mortality (controlled for gender, attained age, lipid-lowering and anti-hypertensive drugs) showed a significant negative association between 1-year IGF1 SDS and SMR for deaths attributed to cardiovascular diseases $(P$ trend $=0.017)$ and malignancies $(P$ trend $=0.044)$, but not to benign tumours $(P$ trend $=0.068)$, infectious diseases $(P$ trend $=0.30)$ or cerebrovascular diseases $(P$ trend $=0.72)$.

Table 3 Mortality rate ratio (RR) by IGF1 SDS category at year 1, adjusted by the final model structure (see Table 2) and additionally the use of anti-lipid drugs. The mortality RR estimates for the IGF1 SDS categories are related to the rates in the category between 0 and +1 IGF1 SDS.

\begin{tabular}{llccc}
\hline IGF1 SDS & $\begin{array}{l}\text { RR } \\
\text { estimate }\end{array}$ & $\mathbf{9 5 \%}$ Cl & $\boldsymbol{\chi}^{\mathbf{2}}$ & $\mathbf{P r}>\boldsymbol{\chi}^{\mathbf{2}}$ \\
\hline$<-2$ & 1.65 & $1.07-2.56$ & 5.06 & 0.024 \\
Between -2 and $<-1$ & 1.12 & $0.90-1.39$ & 1.07 & 0.30 \\
Between -1 and $<0$ & 0.85 & $0.58-1.24$ & 0.73 & 0.39 \\
Between 0 and $<+1$ & 1.00 (ref) & - & - & - \\
Between +1 and $<+2$ & 0.82 & $0.59-1.16$ & 1.25 & 0.26 \\
$\geq+2$ & 0.79 & $0.55-1.14$ & 1.58 & 0.21 \\
\hline
\end{tabular}




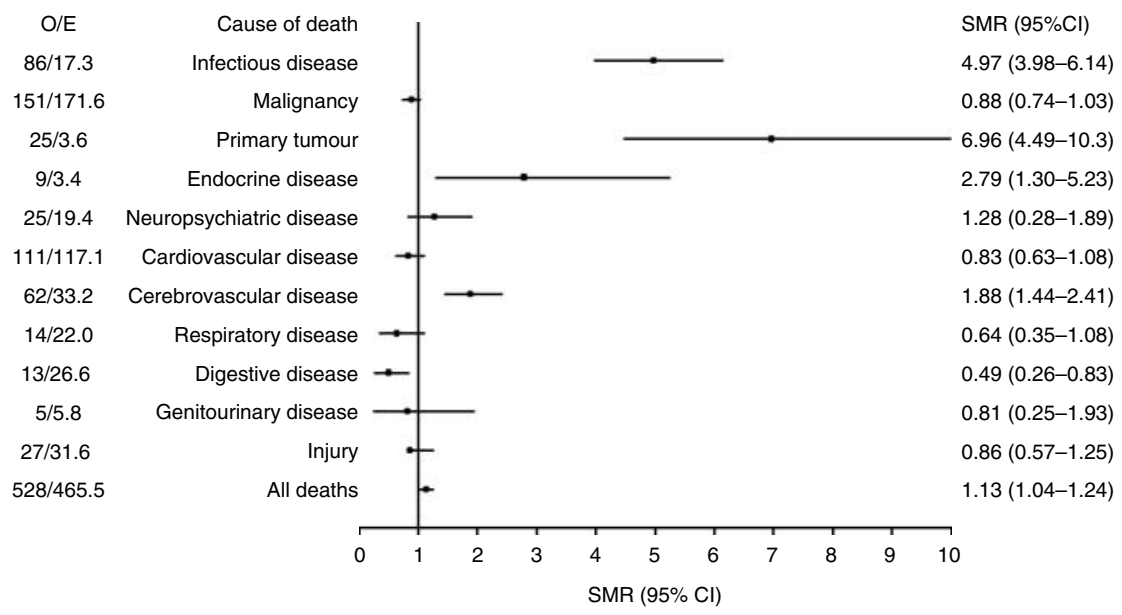

Figure 3 Cause-specific mortality for GH-replaced hypopituitary patients in the KIMS study population compared with the normal population. The SMR (shown as closed circles) and associated $95 \% \mathrm{Cl}$ were plotted for each cause of death. The observed (O) and expected (E) numbers of deaths for each cause of death are also shown.

\section{Discussion}

In this study, we analysed data from the KIMS database to evaluate overall and cause-specific mortality in adult patients with hypopituitarism treated with GH replacement therapy, and to investigate factors associated with mortality in these subjects. In accordance with previous studies in hypopituitary patients $(1,2,3,4,6,8)$, we observed that female gender, younger attained age, underlying diagnosis of craniopharyngioma or aggressive tumour, presence of diabetes insipidus and pretreatment radiotherapy were associated with increased mortality. In contrast to these previous studies, no increased SMR for deaths from cardiovascular diseases or malignancies were observed.

The elevated SMR noted in the studied cohort and the excess mortality seen in female patients confirm the results of earlier studies $(1,2,3,4,6,8)$. That said, the present study revealed a lower SMR in the KIMS study cohort as a whole compared with mortality studies reported in the literature, and an SMR close to 1 in males. The perioperative mortality risk, which would increase the SMR, is not accounted for in the KIMS database since follow-up starts with GH replacement. Nevertheless, in a similar way, SMRs from the literature are usually reported after excluding deaths during the first post-operative month $(1,2,3,4,5)$, although this information is not always available $(6,7,8,9)$. A strict comparison between SMRs is, however, always hazardous as confounding by indication may arise, such as induced by the deliberate choice for GH replacement in the KIMS cohort. A recent meta-analysis of published data on mortality in hypopituitary patients with nonmalignant pituitary disease in whom Cushing's disease and acromegaly were excluded revealed a calculated SMR of 2.06 (95\% CI, 1.94-2.20) for males and of 2.80 (95\% CI, 2.59-3.02) for females (32), higher than the SMR observed in the KIMS study cohort. Whereas the present study did not support a relationship between inadequate sex-steroid replacement in LH/FSH-deficient patients and mortality (4), it suggests that inadequate GH replacement with lower IGF1 concentrations may contribute to the higher mortality observed in hypopituitary women.

The present study revealed increased SMR in younger patients, a finding also noted in previous studies $(2,3,4,8)$. This observation is likely due to the fact that mortality in the general reference population is relatively low in young adults and increases with advancing age. Assuming an absolute constant death rate from a specific disease at different ages, it would result in higher SMR (as a relative measure) in younger ages and lower SMR at older ages because of the increasing background or reference rate. Moreover, even if the death rate from a disease is lower in younger ages compared with older ages, the SMR may anyway be higher in younger ages, because the death rate from the disease increases at a slower pace than the background reference rate increases. Thus, the few deaths encountered in young adults with pituitary disease in this and previous studies resulted in highly elevated SMR due to the low number of deaths expected in this age group.

The primary aetiology of hypopituitarism was strongly associated with SMR in the present study. Craniopharyngiomas, in particular, were associated with an increased SMR, as previously reported but the SMR in the present cohort of GH-replaced hypopituitary adults with craniopharyngioma was lower than that reported previously (SMR, 9.28; 99\% CI, 5.84-14.75) (4). Similarly, the SMR in the sub-group of patients with non-functioning pituitary adenomas included in the present study was similar to unity, while data from the literature have demonstrated a moderately elevated SMR in these patients $(4,5,7,9)$, although not always in males $(7,9)$. An elevated SMR associated with the presence of diabetes insipidus was also noted in the present study, and is probably an expression of the extent of the primary lesion. Whereas we also noted an increase 
in SMR associated with primary radiotherapy, this association must be interpreted with caution $(2,4)$. There are conflicting data on the association of radiotherapy with SMR in hypopituitary patients, with some reporting no effect on $\operatorname{SMR}(1,2)$ and others an increase in mortality (4). Thus, the impact of radiotherapy may be a function of the severity of the primary disease rather than of radiotherapy itself. Similar conclusions may be made for primary transcranial surgery, for which an association with mortality was also found.

In the present analysis of cause-specific mortality, malignancies, cardiovascular disease and cerebrovascular disease were the most common causes of death. Overall, the major difference between this and previous studies of cause-specific mortality is the lower mortality from cardiovascular disease observed in the KIMS study population $(1,3,4,5,6,8)$. However, because $\mathrm{GH}$ replacement therapy is known to have positive effects on several cardiovascular risk factors, it is not clear whether the observed difference in cardiovascular mortality between this and previous studies may be the result of GH replacement only or the result of improved medical care and adequate control of hypertension and hyperlipidaemia. Cerebrovascular mortality, in contrast to cardiovascular mortality, remained elevated in GH-treated patients, but to a lower level (SMR, 1.88; 95\% CI, 1.44-2.41) than the respective SMR of 3.39 (95\% CI, 2.27-4.99) (3), 2.44 (95\% CI, 1.58-4.18) (4), 2.74 (95\% CI, 2.21-3.35) (6) and 2.4 (95\% CI, 1.2-4.7) (8) reported in the literature in non-GH-treated patients with GHD. Whereas the relationship between radiotherapy and cerebrovascular disease was not specifically examined, the observed differences in cardiovascular compared with cerebrovascular SMR may indicate that stroke resulting from radiation vasculopathy is less effectively influenced by $\mathrm{GH}$ replacement (33).

A tendency towards an increased risk of death from infectious diseases in patients with coexisting ACTH deficiency was found in the present study. These findings are consistent with recent data in patients with Addison's disease and stress the need for adequate glucocorticoid replacement combined with appropriate education of patients and health care personnel (34). Whereas previously reported data from the KIMS database have demonstrated a relationship between higher glucocorticoid replacement doses and morbidity (35), these findings did not translate into significantly different overall mortality in ACTH-deficient vs ACTHsufficient patients in the present study.

All patients included in this study received $\mathrm{GH}$ replacement therapy, but because dosing was provided at the discretion of the treating physician, we used IGF1 SDS as a surrogate for the adequacy of GH replacement. One year after enrolment in KIMS, IGF1 SDS in the study cohort was significantly and inversely related to mortality, even after correction for lipid-lowering and anti-hypertensive drugs. We also observed a negative association between GH sensitivity (defined as change in IGF1 SDS from baseline per unit GH dose) and SMR, indicating a potential negative influence of impaired $\mathrm{GH}$ sensitivity on mortality. This observation raises the possibility that comorbidities, such as intercurrent illness, poor nutrition or other as yet unidentified factors, may cause alterations in GH sensitivity that could contribute to mortality. That said, it should be noted that the association between IGF1 SDS and mortality remained significant after correction for prescribed GH dose.

While previous studies retrospectively $(1,2,3,5,6,7$, 8,9 ) or prospectively (4) evaluated all identified patients with hypopituitarism, patients enrolled in KIMS represent a selected group of patients because they are usually already treated for their primary disease, recognised suitable to receive $\mathrm{GH}$ replacement and followed in specialised centres experienced with $\mathrm{GH}$ replacement therapy. This close follow-up of patients in KIMS may be associated with improved overall care. Therefore, we cannot exclude the possibility that patient selection and follow-up in KIMS may by itself influence overall mortality in this cohort. Further, differences in local treatment policies may also influence patient treatment and follow-up and/or reporting of deaths. Cross-country differences were present in the current study, in which countries with centralised medical care showed higher SMR than in Germany, for example, where private medicine is more frequently practised. Despite these confounding issues, the factors identified to be associated with increased mortality in the present analysis of the KIMS study population are almost identical to those found in previous studies.

There is scarce information in the literature regarding the influence of $\mathrm{GH}$ replacement on mortality in hypopituitarism. A previously reported analysis of data from 1903 patients (2334 patient-years) enrolled in KIMS demonstrated an SMR of $0.94(95 \%$ CI, 0.49-1.68) (36). In a study comprising 289 patients (1443 patient-years) from Gothenburg, Sweden, the overall mortality rate, the number of cardiovascular and cerebrovascular events and the occurrence of malignancy were similar to the normal population, although the statistical power of the study was rather low (6). A recent nationwide study in 2229 patients (13 353 patient-years) from The Netherlands demonstrated similar results to those of the present study (37). The reported all-cause SMR in the Dutch study was 1.27 for the total study population (95\% CI, 1.04-1.56), was increased in females (SMR, 1.66; 95\% CI, 1.23-2.23), but was normal in males (SMR, 1.06; 95\% CI, 0.81-1.40). Additional information regarding the cause-specific mortality showed an increase in cardiovascular mortality in females but no increase in malignancy. Confounding factors influencing mortality were a younger age at baseline and an underlying diagnosis of craniopharyngioma or another aggressive aetiology. 
In conclusion, the present study identified several factors associated with increased mortality in the largest population of GH-replaced patients with hypopituitarism investigated to date. Compared with previous reports of mortality in GH-deficient patients, a tendency towards lower SMR was observed. However, a strict assessment of mortality in GH-treated compared with non-treated patients could not be accomplished due to the inevitable absence of a large enough cohort of untreated GHD patients. The amelioration of mortality and its independent association with IGF1 SDS may constitute an indirect indication that $\mathrm{GH}$ replacement is advantageous. Nevertheless, we cannot exclude the possibility that this was the result of impaired $\mathrm{GH}$ sensitivity caused by poor health or due to poor compliance as suggested by the similar prescribed $\mathrm{GH}$ dose in the different groups. These limitations are inherent to a study with a descriptive character. Importantly, GH replacement therapy was not associated with a higher overall SMR than previously reported or with an increased mortality from malignancies and can, on the basis of these and previously published data, be considered a safe treatment in hypopituitary adults with GHD.

\section{Declaration of interest}

R C Gaillard, U Feldt-Rasmussen and R Abs are paid consultants to the KIMS Strategic Advisory Board and members of the KIMS International Board sponsored by Pfizer. B-Å Bengtsson and $\mathrm{J}$ P Monson are members of the KIMS International Board sponsored by Pfizer. A F Mattsson, A-C Åkerblad, J Cara, B Saller and M Kołtowska-Häggström are permanent employees of Pfizer. The statistical analysis was performed by A F Mattsson who is permanently employed by Pfizer Health AB. P Wilton has nothing to disclose and was an employee of Pfizer at the time this manuscript was written but no longer employed by Pfizer. The authors did not receive honoraria for their contribution to this manuscript.

\section{Funding}

The KIMS database is sponsored by Pfizer Inc. Editorial support was provided by Oxford PharmaGenesis Ltd (Oxford, UK) and funded by Pfizer Health AB.

\section{Acknowledgements}

The authors thank the KIMS investigators worldwide who provided the data on their patients and Pfizer colleagues working with the KIMS database.

\section{References}

1 Rosén T \& Bengtsson B-Å. Premature mortality due to cardiovascular disease in hypopituitarism. Lancet 1990336 285-288. (doi:10.1016/0140-6736(90)91812-0)

2 Bates AS, Van't Hoff W, Jones PJ \& Clayton RN. The effect of hypopituitarism on life expectancy. Journal of Clinical Endocrinology and Metabolism $1996 \mathbf{8 1}$ 1169-1172. (doi:10.1210/jc.81.3. 1169)
3 Bülow B, Hagmar L, Mikoczy Z, Nordstrom CH \& Erfurth EM. Increased cerebrovascular mortality in patients with hypopituitarism. Clinical Endocrinology 199746 75-81. (doi:10.1046/j.13652265.1997.d01-1749.x)

4 Tomlinson JW, Holden N, Hills RK, Wheatley K, Clayton RN, Bates AS, Sheppard MC \& Stewart PM. Association between premature mortality and hypopituitarism. West Midlands Prospective Hypopituitary Study Group. Lancet 2001357 425-431. (doi:10.1016/S0140-6736(00)04006-X)

5 Nilsson B, Gustavasson-Kadaka E, Bengtsson B- $\AA$ \& Jonsson B. Pituitary adenomas in Sweden between 1958 and 1991: incidence, survival, and mortality. Journal of Clinical Endocrinology and Metabolism 200085 1420-1425. (doi:10.1210/jc.85.4. 1420)

6 Svensson J, Bengtsson B-Å, Rosén T, Odén A \& Johannsson G. Malignant disease and cardiovascular morbidity in hypopituitary adults with or without growth hormone replacement therapy. Journal of Clinical Endocrinology and Metabolism 200489 3306-3312. (doi:10.1210/jc.2003-031601)

7 Lindholm J, Nielsen EH, Bjerre P, Christiansen JS, Hagen C, Juul S, Jørgensen J, Kruse A, Laurberg P \& Stoch holm K. Hypopituitarism and mortality in pituitary adenoma. Clinical Endocrinology 2006 65 51-58. (doi:10.1111/j.1365-2265.2006.02545.x)

8 Stochholm K, Gravholt CH, Laursen T, Laurberg P, Andersen M, Kristensen LØ, Feldt-Rasmussen U, Christiansen JS, Frydenberg M \& Green A. Mortality and GH deficiency: a nationwide study. European Journal of Endocrinology 2007157 9-18. (doi:10.1530/ EJE-07-0013)

9 Nielsen EH, Lindholm J, Laurberg P, Bjerre P, Christiansen JS, Hagen C, Juul S, Jørgensen J, Kruse A \& Stochholm K. Nonfunctioning pituitary adenoma: incidence, causes of death and quality of life in relation to pituitary function. Pituitary 200710 67-73. (doi:10.1007/s11102-007-0018-x)

10 Sherlock M, Ayuk J, Tomlinson JW, Toogood AA, Aragon-Alonso A, Sheppard MC, Bates AS \& Stewart PM. Mortality in patients with pituitary disease. Endocrine Reviews 201031 301-342. (doi:10.1210/er.2009-0033)

11 Abs R, Bengtsson B-Å, Hernberg-Ståhl E, Monson JP, Tauber JP, Wilton P \& Wüster C. GH replacement in 1034 growth hormone deficient hypopituitary adults: demographic and clinical characteristics, dosing and safety. Clinical Endocrinology 199950 703-713. (doi:10.1046/j.1365-2265.1999.00695.x)

12 Abdu TA, Neary R, Elhadd TA, Akber M \& Clayton RN. Coronary risk in growth hormone deficient hypopituitary adults: increased predicted risk is due largely to lipid profile abnormalities. Clinical Endocrinology 200155 209-216. (doi:10.1046/j.1365-2265. 2001.01320.x)

13 Rosén T, Eden S, Larson G, Wilhelmsen L \& Bengtsson B-Å. Cardiovascular risk factors in adult patients with growth hormone deficiency. Acta Endocrinologica 1993129 195-200.

14 Beshyah SA, Henderson A, Niththyanathan R, Sharp P, Richmond W \& Johnston DG. Metabolic abnormalities in growth hormone deficient adults, II. Carbohydrate tolerance and lipid metabolism. Endocrinology and Metabolism 19941 173-180.

15 Lonn L, Kvist H, Grangard U, Bengtsson B-Å \& Sjöström L. CT-determined body composition changes with recombinant human growth hormone treatment to adults with growth hormone deficiency. Basic Life Science 199360 229-231.

16 Beshyah SA, Freemantle C, Thomas E, Rutherford O, Page B, Murphy $M$ \& Johnston DG. Abnormal body composition and reduced bone mass in growth hormone deficient hypopituitary adults. Clinical Endocrinology 199542 179-189. (doi:10.1111/j. 1365-2265.1995.tb01860.x)

17 Hew FL, Koschmann M, Christopher M, Rantzau C, Vaag A, Ward G, Beck-Nielsen H \& Alford F. Insulin resistance in growth hormone-deficient adults: defects in glucose utilization and glycogen synthase activity. Journal of Clinical Endocrinology and Metabolism 199681 555-564. (doi:10.1210/jc.81.2.555) 
18 Johansson JO, Landin K, Tengborn L, Rosén T \& Bengtsson B-Å. High fibrinogen and plasminogen activator inhibitor activity in growth hormone-deficient adults. Arteriosclerosis, Thrombosis, and Vascular Biology 199414 434-437. (doi:10.1161/01.ATV.14.3.434)

19 McCallum RW, Petrie JR, Dominiczak AF \& Connell JM. Growth hormone deficiency and vascular risk. Clinical Endocrinology 2002 57 11-24. (doi:10.1046/j.1365-2265.2002.01559.x)

20 Evans LM, Davies JS, Goodfellow J, Rees JA \& Scanlon MF. Endothelial dysfunction in hypopituitary adults with growth hormone deficiency. Clinical Endocrinology 199950 457-464. (doi:10.1046/j.1365-2265.1999.00671.x)

21 Pfeifer M, Verhovec R, Zizek B, Prezelj J, Poredos P \& Clayton RN. Growth hormone $(\mathrm{GH})$ treatment reverses early atherosclerotic changes in GH-deficient adults. Journal of Clinical Endocrinology and Metabolism 199984 453-457. (doi:10.1210/jc.84.2.453)

22 Cuneo RC, Salomon F, Watts GF, Hesp R \& Sonksen PH. Growth hormone treatment improves serum lipids and lipoproteins in adults with growth hormone deficiency. Metabolism $1993 \mathbf{4 2}$ 1519-1523. (doi:10.1016/0026-0495(93)90145-E)

23 Götherström G, Bengtsson B-A, Bosaeus I, Johannsson G \& Svensson J. A 10-year, prospective study of the metabolic effects of growth hormone replacement in adults. Journal of Clinical Endocrinology and Metabolism $2007 \quad 92 \quad 1442-1445$. (doi:10.1210/jc.2006-1487)

24 Colao A, di Somma C, Pivonello R, Cuocolo A, Spinelli L, Bonaduce D, Salvatore M \& Lombardi G. The cardiovascular risk of adult GH deficiency (GHD) improved after GH replacement and worsened in untreated GHD: a 12-month prospective study. Journal of Clinical Endocrinology and Metabolism 200287 1088-1093. (doi:10.1210/jc.87.3.1088)

25 Ongoing safety review of Recombinant Human Growth Hormone (somatropin) and possible increased risk of death. US Food and Drug Administration (FDA), Safety Communication, December $12,2010$.

26 Gutiérrez LP, Kołtowska-Häggström M, Jönsson PJ, Mattsson AF, Svensson D, Westberg B \& Luger A. Registries as a tool in evidence-based medicine: example of KIMS (Pfizer International Metabolic Database). Pharmacoepidemiology and Drug Safety 2008 17 90-102. (doi:10.1002/pds.1510)

27 Ho KK. Consensus guidelines for the diagnosis and treatment of adults with GH deficiency II: a statement of the $\mathrm{GH}$ Research Society in association with the European Society for Pediatric Endocrinology, Lawson Wilkins Society, European Society of Endocrinology, Japan Endocrine Society, and Endocrine Society of Australia. European Journal of Endocrinology 2007157 695-700. (doi:10.1530/EJE-07-0631)

28 The global burden of disease: 2004 update. In WHO Library Cataloguing-in-Publication Data. 1.Cost of illness. 2.World health statistics. 3.Mortality - trends. I. World Health Organization. ISBN 9789241563710 (NLM classification: W 74).
29 Underwood LE \& Murphy MG. Radioimmunoassay of the somatomedins/insulin-like growth factors. In Radioimmunoassay in Basic and Clinical Pharmacology, pp 561-574. Eds C Patrano \& BA Peskar, Berlin: Springer-Verlag, 1987.

30 Brabant G, von zur Mühlen A, Wüster C, Ranke MB, Kratzsch J, Kiess W, Ketelslegers JM, Wilhelmsen L, Hulthén L, Saller B, Mattsson A, Wilde J, Schemer R \& Kann P \& German KIMS Board. Serum insulin like growth factor I reference values for an automated chemiluminescence immunoassay system: results from a multicenter study. Hormone Research 200360 53-60. (doi:10.1159/000071871)

31 Breslow D. The design and analysis of cohort studies. In Statistical Methods in Cancer Research, vol 2, p. 69. Eds NE Breslow \& NE Day, Lyon: IARC Scientific Publications, 1987.

32 Nielsen EH, Lindholm J \& Laurberg P. Excess mortality in women with pituitary disease: a meta-analysis. Clinical Endocrinology 200767 693-697. (doi:10.1111/j.1365-2265.2007. 02947.x)

33 Plummer C, Henderson RD, O'Sullivan JD \& Read SJ. Ischemic stroke and transient ischemic attack after head and neck radiotherapy: a review. Stroke $2011 \mathbf{4 2}$ 2410-2418. (doi:10.1161/ STROKEAHA.111.615203)

34 Bergthorsdottir R, Leonsson-Zachrisson M, Odén A \& Johannsson G. Premature mortality in patients with Addison's disease: a population-based study. Journal of Clinical Endocrinology and Metabolism 200691 4849-4853. (doi:10.1210/jc.20060076)

35 Filipsson H, Monson JP, Kołtowska-Häggström M, Mattsson AF \& Johannsson G. The impact of glucocorticoid replacement regimens on metabolic outcome and comorbidity in hypopituitary patients. Journal of Clinical Endocrinology and Metabolism 200639 3954-3961. (doi:10.1210/jc.2006-0524)

36 Bengtsson B- $\AA$, Abs R, Bennmarker H, Monson JP, FeldtRasmussen U, Hernberg-Ståhl E, Westberg B, Wilton P \& Wüster $C$. The effects of treatment and the individual responsiveness to growth hormone $(\mathrm{GH})$ replacement therapy in 665 GH-deficient adults. Journal of Clinical Endocrinology and Metabolism 199984 3929-3935. (doi:10.1210/jc.84.11.3929)

37 van Bunderen CC, van Nieuwpoort IC, Arwert LI, Heymans MW, Franken AA, Koppeschaar HP, van der Lely AJ \& Drent ML. Does growth hormone replacement therapy reduce mortality in adults with growth hormone deficiency? Data from the Dutch national registry of growth hormone treatment in adults. Journal of Clinical Endocrinology and Metabolism $2011963151-$ 3159. (doi:10.1210/jc.2011-1215)

Received 29 November 2011

Revised version received 13 March 2012

Accepted 28 March 2012 